\section{Saccular sensitivity to sound}

Dear Sirs,

We read with great interest the article by Kanegaonkar and colleagues entitled 'The contribution of hearing to normal balance', ${ }^{1}$ published recently in The Journal of Laryngology \& Otology. In this article, Kanegaonkar et al. describe their findings, and they indicate that, although it is recognised that visual input, proprioception and peripheral vestibular system input play a central role in maintaining posture, ambient sound and hearing may also have a significant influence.

That sound has an effect on the maintenance of orientation is elegantly shown in this study. However, we would like to alert your readers to the fact that this phenomenon may still be related to the triad of vision, proprioception and vestibular system input, especially the latter. It is becoming increasingly recognised that the saccule, which is a vestibular organ, is stimulated by sound, especially low frequency sound.

In recent years, it has been increasingly acknowledged that the saccule not only responds best to low frequency sound, but may in fact at least contribute to the hearing of this frequency band. ${ }^{2}$ Evidence accumulated over the last few decades supports the case that the saccule has conserved an acoustic sensitivity throughout vertebrate phylogeny; indeed, electrophysiological assessment of vestibular function using vestibular evoked myogenic potentials takes advantage of this phenomenon. ${ }^{3}$ It is possible that saccular stimulation contributes to the affective quality of loud sounds, ${ }^{4}$ and it has been shown that the vestibular system in mice can mediate the detection of low frequency sounds. ${ }^{5}$

We believe that Kanegaonkar and colleagues' article makes a significant contribution not only to the theory that sound may play a role in orientation, but also to the argument that the saccule, which is itself sensitive to sound, may mediate this phenomenon.

\section{DR. ELEFTHERIOS S PAPATHANASIOU}

Clinic B, The Cyprus Institute of Neurology and Genetics, P.O. Box 23462, Nicosia 1683,

Cyprus

Tel: $+357-22-358600$

Fax: $+357-22-358238$

E-mail: neurophy@cing.ac.cy

\section{References}

1 Kanegaonkar RG, Amin K, Clarke M. The contribution of hearing to normal balance. J Laryngol Otol 2012;126:984-8

2 Todd N. Evidence for a behavioural significance of saccular acoustic sensitivity in humans. J Acoust Soc Am 2001;110: $380-90$

3 Colebatch JG, Halmagyi GM. Vestibular evoked potentials in human neck muscles before and after unilateral vestibular deafferentation. Neurology 1992;42:190-7

4 Todd NPM, Cody F. Vestibular responses to loud dance music: a physiological basis for the "rock and roll threshold"? J Acoust Soc Am 2000;107:496-500

5 Jones GP, Lukashkina VA, Russell IJ, Lukashkin AN. The vestibular system mediates sensation of low-frequency sounds in mice. $J$ Assoc Res Otolaryngol 2010;11:725-32 